\title{
COMPATIBLE VOLUME-TAPER EQUATIONS FOR PREDICTING MERCHANTABLE VOLUME TO VARIABLE MERCHANTABLE LIMITS FOR CUPRESSUS LUSITANICA, ETHIOPIA
}

\author{
Tesfaye Teshome * \\ Debub University, PO BOX 5, Awassa, Ethiopia. E-mail: henos_tesfaye@yahoo.com
}

\begin{abstract}
Compatible systems of merchantable total tree cubic volume and stem taper equations are derived by integrating an existing volume equation. The systems are developed to yield volume at any merchantable length, total volume and for any merchantable top diameter. It is also demonstrated that the most common types of volume equation can be converted to compatible taper equation.
\end{abstract}

Key words/phrases: Merchantable volume, compatible volume, taper equations

\section{INTRODUCTION}

Total tree volume has often been estimated using existing volume equations for a long time and might continue to be used in the future. They, however, do not give quantitative information on the amount of wood for a specific use standard, that is, the amount of saw timber, pulp and fuel wood an individual tree produces. Forest managers and forest product manufacturing companies are often more interested in estimating merchantable volumes, as the profitability of their enterprises heavily depends on reliable estimates of merchantable volume. Hence a system that is simple, accurate and flexible should be designed to estimate merchantable volume of any section, height for any diameter, and diameter for any height based on only easily measurable parameters such as diameter at breast height and height. A mathematical stem profile equation (taper equation), which can be integrated to volume, can usually meet these requirements.

Taper is the form used to describe the decrease in stem diameter with increasing height up the stem (Clutter et al. 1983). When tree diameters at certain intervals are measured a taper curve or stem profile can be drawn from the measurements. From the resulting curve (taper line) one can find the diameter for any section of the tree and calculate the volume for each section using one of the standard volume formulas. This taper line can be mathematically expressed as a taper equation. In a taper equation, diameter at any height (d) is predicted as a function of diameter at breast height (dbh), total height $(\mathrm{H})$, and section length $(\mathrm{L})$. This concept can be mathematically expressed as $\mathrm{d}=\mathrm{f}$ (dbh, H, L).

If the taper line is rotated about the height axis a three dimensional solid of the stem shape appears. Philip (1994) called this three-dimensional figure as "solid of revolution". The volume $\left(\mathrm{V}_{2}\right)$ of the solid of revolution is obtained by summing up the volumes of a series of thin cross sectional slices and lengths along the entire stem height. This is achieved by integrating $\mathrm{d}$ with respect to $\mathrm{L}$. Some of the previous works from Bruce et al. (1968), Kozak et al. (1969), Demaerschalk (1973), Clutter (1980) and Reed and Green (1984) could be cited as examples. This taper equation can also be used to compute sectional volumes at any part of the tree if integrated between the appropriate limits.

However, as noted by Demaerschalk (1973), although many taper equations developed by mensurationists have resulted in a good estimate of taper, the estimation of volume was usually less satisfactory because of bias. The biases on taper estimates vary considerably with the position in the tree and with the size of the tree. Most systems in use are incompatible and cause problems especially in biomass studies where various component volumes or weights of the tree are estimated individually. In such situations, development of a taper equation that gives the best possible estimate for taper while also being compatible with the existing volume equation is highly recommended. When volume equation is used together with a taper equation, it is called ' a volume-taper estimating system' (Munro and

\footnotetext{
* Current address: Higher Education Relevance and Quality Agency, MOE, Addis Ababa.
} 
Demaerschalk, 1974). The system is called "compatible" if $V_{1}=V_{2}\left(V_{1}\right.$ is volume from the volume equation and $V_{2}$ volume derived from the taper equation) for all trees with the same diameter at breast height and length. In contrast when this is not fulfilled, the system is said to be 'incompatible'.

Demaerschalk (1973), Munro and Demaerschalk (1974), and Evert (1976) discussed the advantages of a volume-taper estimation system. According to Munro and Demearschalk (1974) the most important benefit of a compatible system is to obtain consistent results from both volume and taper equations. The two most important ways to construct a compatible system are: the volumebased system and taper-based system. In their discussion Munro and Demaerschalk (1974) emphasised that there is no such thing as the best system. A totally unbiased taper equation does not exist. On the other hand they noted that volumebased systems, if derived from sufficiently unbiased volume equations will always be satisfactory for total volume estimation.

The purpose of this study is, therefore, to develop a compatible volume and taper system for Cupressus lusitanica stands in Munessa Shashemene Forest, Ethiopia. The system is a volume based because the compatible taper equation is derived from volume equation. A general procedure to convert logarithmic volume equation to compatible taper equation is presented using taper data collected from Cupressus lusitanica stands in Munessa Shahsemene Forest, Ethiopia.

\section{DATA AND METHOD}

\section{Data}

A total of 46 circular plots with radius of $11.28 \mathrm{~m}$ were laid out in a wide range of sites and ages. Five trees nearest to the centre of the sample plots were selected for stem analysis in order to collect the taper and merchantable volume data. The diameter at breast height $(\mathrm{dbh}, \mathrm{cm})$ was measured on each of the 243 sample trees, and the trees were then felled and cut into five sections of equal length $(1 / 10,3 / 10,5 / 10,7 / 10$ and $9 / 10)$ for the total height of individual trees between a $30 \mathrm{~cm}$ stump height and the tip of the tree. The top limiting diameter $(\mathrm{d}, \mathrm{cm})$ and corresponding length $(\mathrm{L}, \mathrm{m})$ from the tip of the tree downwards were measured at five positions (as stated above) of the total height of individual trees. The taper and merchantable volume data collected and summary statistics for Cupressus lusitanica stands are presented in Table 1 . The site index equation developed by Tesfaye Teshome and Petty (2000) was used to determine site quality of stands.

The two important tending operations given to Cupressus lusitanica stands are pruning and thinning. Most stands in Munessa Sahshemene Forest Project are thinned and pruned in the project to ensure quality production of timber free of knots as C. lusitanica has persistent branches. The fitted volume-taper equations could be used in thinned and pruned stands.

Table 1. Summary statistics of the taper data and stand parameters.

\begin{tabular}{lllll}
\hline Variables & Minimum & Mean & Maximum & $\begin{array}{l}\text { Standard } \\
\text { dev. }\end{array}$ \\
\hline Age (years) & 6.0 & 14.5 & 25.0 & 5.5 \\
dbh $(\mathrm{cm})$ & 4.0 & 18.6 & 34.3 & 6.21 \\
$\mathrm{H}(\mathrm{m})$ & 5.25 & 16.59 & 29.5 & 5.38 \\
$\mathrm{~L}(\mathrm{~m})$ & 0.53 & 9.61 & 28.0 & 6.2 \\
$\mathrm{~V}\left(\mathrm{~m}^{3}\right)$ & 1.0943 & 0.2570 & 0.0049 & 0.2235 \\
$\mathrm{H}_{\text {dom }}(\mathrm{m})$ & 6.9 & 19.8 & 32.4 & 5.9 \\
Site index $(\mathrm{m})$ & 12.0 & 18.6 & 27.0 & 3.7 \\
\hline
\end{tabular}

\section{Method}

\section{Deriving the compatible taper equation from the volume equation}

In this study, the Cupressus lusitanica volume equation developed by Tesfaye Teshome (1996) was adopted as the basis for the derivation of compatible taper equation. Equation 1 was validated and its precision estimated. An external validation of the volume equation using test data, which was not used for model construction, was also undertaken. The mean bias calculated was $0.00428 \mathrm{~m}^{3}$ and is considered to be negligible for practical forest management. The standard deviation (S) of the mean bias, which measures the precision, is $0.0293 \mathrm{~m}^{3}$. Thus, the true differences between the observed and predicted volume lie within $\pm 3 \%$ of the mean observed volume. The precision obtained was as expected as volume error was generally less than $4 \%$ of true volume, as might be evident from the high coefficient of determination $\left(\mathrm{R}^{2}=96.2 \%\right)$ and the simple nature of the volume predicting equation. Thus, Equation 1 has been used as the basis for the derivation of compatible taper equation in this study. The logarithmic volume equation adopted is

$$
\log \left(V_{1}\right)=a+b \log (d b h)+c \log (H)
$$

which can be easily converted into a logarithmic taper equation (Demaerschalk, 1973; Mc Tague and Bailey, 1986). 


$$
\log (d)=b_{0}+b_{1} \log (d b h)+b_{2} \log (H)+b_{3} \log (L)
$$

where: $\mathrm{dbh}=$ diameter at breast height $(\mathrm{cm})$

$\mathrm{H}=$ total height $(\mathrm{m})$

$\mathrm{d}=$ diameter $(\mathrm{cm})$ at length $\mathrm{L}(\mathrm{m})$

$\mathrm{L}=$ distance $(\mathrm{m})$ from the tip of the tree downwards $\mathrm{a}, \mathrm{b}, \mathrm{c}, \mathrm{b}_{0}, \mathrm{~b}_{1}, \mathrm{~b}_{2}, \mathrm{~b}_{3}=$ regression coefficients

Equation (2) can also be written as;

$$
d=10^{b_{o}} d b h^{b_{1}} H^{b_{2}} L^{b_{3}}
$$

or

$$
d^{2}=10^{2 b_{o}} d b h^{2 b_{1}} H^{2 b_{2}} L^{2 b_{3}}
$$

The volume $\left(\mathrm{V}_{2}\right)$ of a single tree can also be calculated by summing up the volume of small slices of known length (L), and diameter (d) along the stem using integration.

This is accomplished by integrating $\mathrm{d}$ with respect to $\mathrm{L}$ (equation $3 \mathrm{~b}$ ) because it is mathematically convenient to use diameter squared as dependent variable rather than diameter in taper equation (Clutter, 1980):

$$
V_{2}=\frac{\Pi}{4} 10^{-4} \int_{0}^{H} d^{2} d l
$$

Substituting the right side of equation ( $3 b)$ into equation (4) in place of $d^{2}$ provides:

$$
\begin{aligned}
& V_{2}=\frac{\prod}{4} 10^{-4} \int_{0}^{H} 10^{2 b_{0}} d b h^{2 b_{1}} H^{2 b_{2}} L^{2 b_{3}} d l \\
& =\frac{\prod}{4} 10^{-4} 10^{2 b_{0}} d b h^{2 b_{1}} H^{2 b_{2}} \int_{0}^{H} L^{2 b_{3}} d l \\
& =\frac{\prod}{4} 10^{-4} 10^{2 b_{0}} d b h^{2 b_{1}} H^{2 b_{2}}\left[L^{2 b_{3}+1}\right]_{0}^{H} / 2 b_{3}+1 \\
& \text { when } \\
& \text { L }=\mathrm{H} \\
& V_{2}=\frac{\prod}{4} 10^{2 b_{0}-4} d b h^{2 b_{1}} H^{2 b_{2}} H^{2 b_{3}+1} / 2 b_{3}+1 \\
& =\frac{\prod}{4} 10^{2 b_{0}-4} d b h^{2 b_{1}} H^{2 b_{2}+2 b_{3}+1} / 2 b_{3}+1
\end{aligned}
$$

Let $\mathrm{K}=\frac{\prod}{4} 10^{2 b_{0}-4} / 2 b_{3}+1$

Then

$$
V_{2}=K d b h^{2 b_{1}} H^{2 b_{2}+2 b_{3}+1}
$$

After taking the logarithm,

$$
\begin{array}{r}
\log \left(V_{2}\right)=\log (K)+2 b 1 \log (d b h) \\
+\left(2 b_{2}+2 b_{3}+1\right) \log (H) \ldots
\end{array}
$$

The justification by which the logarithmic taper equation is derived from the logarithmic volume equation is based on the premise that total volume estimates $\left(V_{2}\right)$ by equation (6), based on integration of the taper equation, must be identical to those $\left(V_{1}\right)$ obtained by the volume equation (1). From the above mathematical formulation it is noticeable that equation (1) and equation (6) are identical when:

$$
\begin{aligned}
& a=\log (K) \ldots \ldots \ldots \ldots \\
& \mathrm{b}=2 \mathrm{~b}_{1} \ldots \ldots \ldots \ldots \ldots \ldots \ldots \ldots \ldots \ldots \\
& \mathrm{c}=2 \mathrm{~b}_{2}+2 \mathrm{~b}_{3}+1 .
\end{aligned}
$$

Moreover the coefficients of the taper equation (2) must be expressed in terms of the coefficients of the volume equation (1) viz. $a, b$, and $c$ and one 'free parameter', fp as noted by Demaerschalk (1973), which is a unique value for a given set of taper data. The parameter (fp) expresses the variability of $d$ along the stem and depends on the diameter at breast height $(\mathrm{dbh})$, total height $(\mathrm{H})$ and the length (L) from the tip of the tree downwards. Hence the free parameter (fp) which gives the best fit for the cypress taper data was 
estimated by a least squares procedure (nonlinear) so as to minimize the standard error of the estimate $(\mathrm{SEE})$ of diameter d along the stem. Derivative free non-linear regression routine of BMDP (1990) was used to minimize the standard error of the estimate of the diameter along the bole.

Let

$2 \mathrm{~b}_{3}+1=\mathrm{fp}^{*} \mathrm{C}$

From equation (7)

$$
\begin{aligned}
\mathrm{a} & =\log (\mathrm{K}) \\
& =\log \left(\frac{\Pi}{4} 10^{2 b_{0}-4} / f p^{*} c\right)
\end{aligned}
$$

solving for $\mathrm{b}_{0}$ gives

$$
b_{0}=1 / 2 *\left[\log \left(\frac{4}{\Pi} f p^{*} c 10^{a+4}\right)\right]
$$

From equation (8)

$$
b_{1}=b / 2
$$

From equation (9)

$$
b_{2}=c(1-f p) / 2
$$

From equation (10)

$$
b_{3}=(f p * c-1) / 2
$$

Thus, with the exception of the free parameter (fp) of the taper equation, all the parameters are known and expressed in terms of the volume equation coefficients (Equation 1).

\section{Derivation of merchantable tree volume to any} limiting top-diameter

The compatible taper equation (3a)

$$
d=10^{b_{0}} d b h^{b_{1}} H^{b_{2}} L^{b_{3}}
$$

is used to predict merchantable volume to limiting top diameters $(e . g ., \mathrm{d}=15 \mathrm{~cm})$.
Equation (3a) can be algebraically rearranged to estimate the distance $\mathrm{L}$ from the tip of the tree to any specific limiting top-diameter (d):

$$
L=10^{\frac{-b_{0}}{b_{3}}} * d^{\frac{1}{b_{3}}} d b h^{\frac{-b_{1}}{b_{3}}} H^{\frac{-b_{2} *}{b_{3}}}
$$

The volume $\left(\mathrm{V}_{\mathrm{L}}\right)$ to a specific distance $\mathrm{L}$ from the tip of the tree downwards can be calculated as follows (see the derivation and symbols as stated above):

$$
V_{L}=K d b h^{2 b_{1}} H^{2 b_{2}} L^{2 b_{3}+1}
$$

The compatible taper equation after being integrated with respect to $\mathrm{L}$, gives the total volume $\left(V_{t}\right)$ when total height $(\mathrm{H})$ equals a given length $(\mathrm{L})$ as derived in equation (5):

$$
V_{t}=K d b h^{2 b_{1}} H^{2 b_{2}+2 b_{3}+1}
$$

The merchantable volume $\left(\mathrm{V}_{\mathrm{m}}\right)$ to limiting topdiameter $\mathrm{d}$ is therefore the difference between $\mathrm{V}_{t}$ and $\mathrm{V}_{\mathrm{L}}$ :

$$
V_{m}=V_{t}-V_{L}
$$

Substituting the right sides of equation 12 and 13 in equation 14 we get:

$$
V_{m}=K d b h^{2 b_{1}} H^{2 b_{2}}\left\lfloor H^{2 b_{3}+1}-L^{2 b_{3}+1}\right\rfloor .
$$

Substituting

$$
\left(10^{-b_{0}} d * d b h^{-b_{1}} H^{b_{2}}\right)^{1 / b_{3}}
$$

from equation 11 for $\mathrm{L}$ in equation 15, we get:

$$
V_{m}=K d b h^{2 b_{1}} H^{2 b_{2}}\left[H^{2 b_{3}+1}-\left(10^{-b_{0}\left(\frac{2 b_{3}+1}{b_{3}}\right)} d^{\left(\frac{2 b_{3}+1}{b_{3}}\right)} d b h^{-b_{1}\left(\frac{2 b_{3}+1}{b_{3}}\right)} H^{-b_{2}\left(\frac{2 b_{3}+1}{b_{3}}\right)}\right]\right)
$$


Equation 16 predicts the merchantable volume to any limiting top diameter provided the coefficients of the taper equations $\left(b_{0}, b_{1}, b_{2}\right.$ and $\left.b_{3}\right)$, diameter at breast height and total height of individual trees are known.

BMDP (1990) Statistical Software Manual and Minitab (1995) User's guide, Release 10Xtra for Window's ${ }^{\mathrm{TM}}$ and Macintosh ${ }^{\mathrm{R}}$ were used in this study. Non-linear derivative free routine of BMDP was used for all non-linear equations while Minitab was used for all linear equations and the coefficients were significant at $\mathrm{P}=0.05$.

\section{RESULTS AND DISCUSSION}

\section{Fitting taper data}

The taper data were used to estimate the initial values of the coefficients using the statistical package MINITAB. These initial values were later on used to estimate the coefficients of the taper equation using a nonlinear regression package,
BMDP. The taper equation, which fits best these particular taper data, is:

$$
\begin{array}{r}
\log (\mathrm{d})=0.031+0.559 \log (\mathrm{dbh})+-0.448 \log (\mathrm{H}) \\
+0.929 \log (\mathrm{L}) \quad \ldots \ldots \ldots \ldots \ldots \ldots \ldots \ldots \ldots \ldots \ldots \ldots \ldots \ldots \ldots \ldots \ldots \ldots \\
\mathrm{R}^{2}=0.92 \quad \mathrm{~S}_{\mathrm{EE}}=0.105 \quad \text { RSS }=12.80
\end{array}
$$

The result shows that the taper model is acceptable as the coefficient of determination value $\left(R^{2}\right)$ is high, standard error of the estimate $\left(S_{E E}\right)$ and the residual sum of squares (RRS) are small. Moreover, it is found that the distribution of the residual against the predicted $\mathrm{d}$ values is homogeneous and free of any type of systematic trend (Figure 1) The same data were analysed using BMDP statistical package to estimate $\mathrm{fp}$. The value of $\mathrm{fp}$ with the smallest standard error of estimate of $\mathrm{d}$ was found to be 1.539. The equation used to estimate the free parameter $\mathrm{fp}$ is

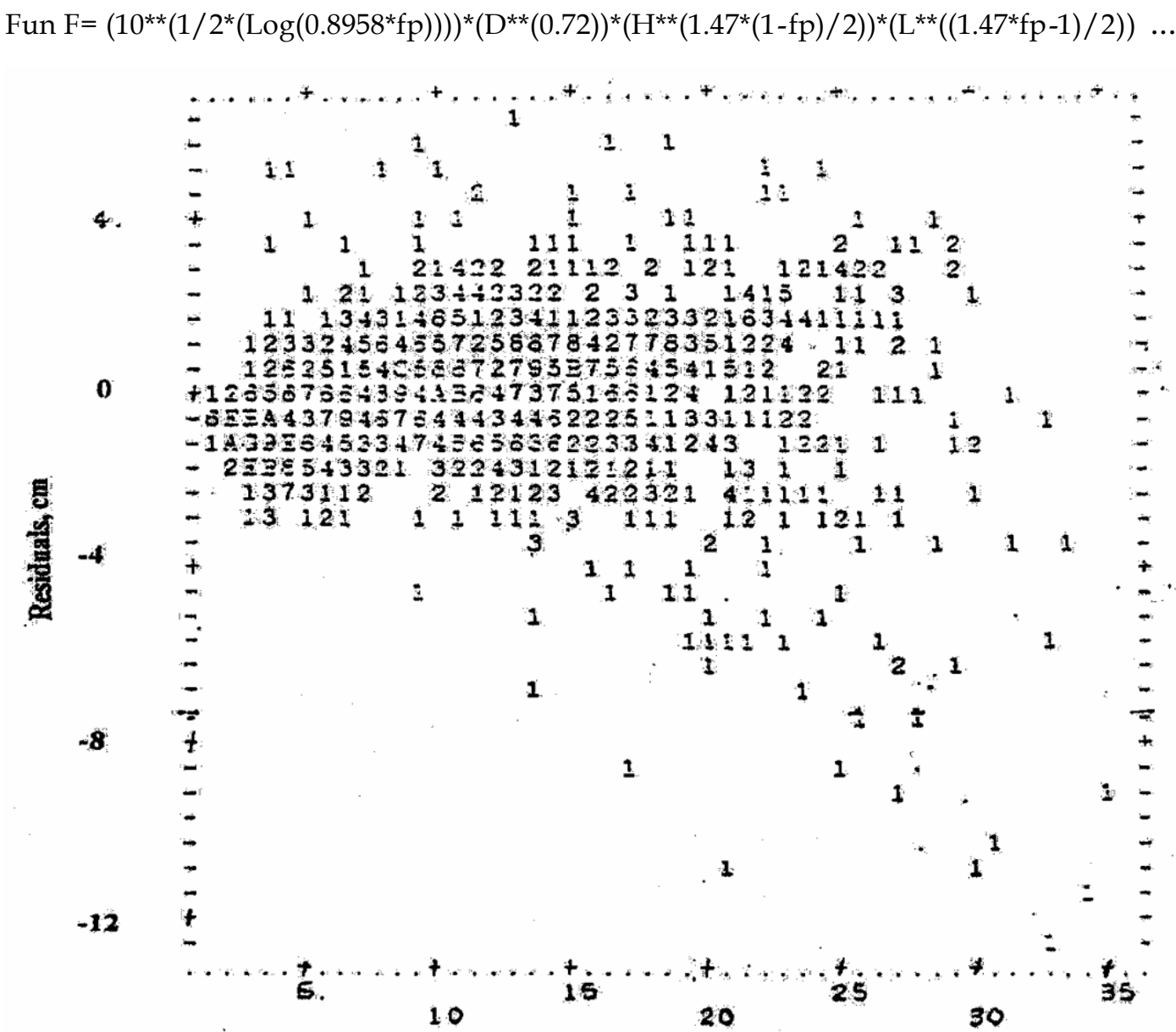

d-over bark, cm

Fig. 1. Residual distribution against the observed d-over bark-values. 
The BMDP program control information used to estimate the free taper parameter (fp) for the tape data is not given here for briefness.

Thus;

$$
\begin{aligned}
\mathrm{b}_{0} & =1 / 2\left(\log \left(10^{\mathrm{a}+4} .4 . \mathrm{fp} . \mathrm{c} / \Pi\right)\right) \\
& =1 / 2\left(\log \left(10^{-4.32+4} \cdot 4 \cdot 1 \cdot 539 \cdot 1 \cdot 47 / \Pi\right)\right) \\
& =0.0697
\end{aligned}
$$

$$
\mathrm{b}_{1}=\mathrm{b} / 2=1.44 / 2=0.72
$$$$
\mathrm{b}_{2}=\mathrm{c}(1-\mathrm{fp}) / 2=1.47(1-1.539) / 2
$$$$
=-0.3961
$$

$b_{3}=(f p c-1) / 2=(1.539 .1 .47-1) / 2=0.6312$
The compatible taper equation is equation $3 a$ with the new $b$ values. Thus the taper equation that predicts the limit top diameter $\mathrm{d}$ is;

$$
\left.\mathrm{d}=1.17409^{*} \mathrm{dbh}^{0.72} \mathrm{H}^{-0.3961} \mathrm{~L}^{0.6312}\right)
$$

while the taper equation that predicts the merchantable length at which the limit top diameter is obtained by rearranging equation 19 in terms of $\mathrm{L}$ :

$$
L=0.7755 * d^{1.5843} d b h^{-1.1407} H^{0.6275}
$$

Having derived the merchantable volume estimation equation, equation 16 , the values of the parameters are calculated as follows;

$$
K=\frac{\prod}{4} 10^{2 b_{0}-4} / 2 b_{3}+1=0.0000478
$$

$$
2 b_{1}=1.44 ; \quad 2 b_{2}=-0.7924 ; \quad 2 b_{3}+1=2.2624
$$

$$
10-b_{0}\left(2 b_{3}+1\right) / b_{3}=0.5626 ; \quad\left(2 b_{3}+1\right) / b_{3}=3.584
$$

$$
-b_{1}\left(2 b_{3}+1\right) / b_{3}=-2.581 ; \quad-b_{2}\left(2 b_{3}+1\right) / b_{3}=1.42
$$

$V_{m}=0.0000478 * d b h^{0.72} H^{-0.7924}\left[H^{2.2624}-0.5626 d^{3.584} d b h^{-2.581} H^{1.42}\right]$

Thus equation 21 with the above coefficients predicts the merchantable volume to a given limit top diameter (d) in this study. 


\section{APPLICATION}

The application of the merchantable volume estimation equation is immense in assortment of total volume for different uses in forest management. For instance if the diameter at breast height (dbh), total height $(\mathrm{H})$ and merchantable top diameter (d) are given, it is easy to estimate the saw log, pulp wood and fuel wood portions from the total volume of individual trees. The following example illustrates this:

Let $\quad d b h=28.5 \mathrm{~cm}$

Total height $(\mathrm{H})=19.3 \mathrm{~m}$

Merchantable top diameter $(\mathrm{d})=15 \mathrm{~cm}$

Tree total volume $=0.461502 \mathrm{~m}^{3}$ as estimated by the volume equation (Tesfaye Teshome, 1996) or equation 13.

Merchantable volume contained by a $15 \mathrm{~cm}$ top diameter (Saw $\log , \mathrm{m}^{3}$ ) would be 0.39962 . The difference between the total volume and merchantable volume is either pulpwood or fuel wood. Given the pulp wood specification (e.g., $\mathrm{d}$ lies between 15 and $10 \mathrm{~cm}$ ); the pulp wood volume would be $0.0474 \mathrm{~m}^{3}$ while fuel wood amounts $0.0145 \mathrm{~m}^{3}$. The sum of the merchantable volumes $\left(0.46152 \mathrm{~m}^{3}\right)$ equals the volume obtained from volume equation (Tesfaye Teshome, 1996) or when the limit top diameter $\mathrm{d}$ is set to be equal to zero in the merchantable volume equation (Equation 21).

The length at which the top diameter $15 \mathrm{~cm}$ is obtained is estimated using the taper equation (Equation 20) to be at $7.95 \mathrm{~m}$. Any top diameter (e.g., $\mathrm{d}=15 \mathrm{~cm})$ for any specific use can also be predicted and obtained for any given length (e.g., L $=7.94 \mathrm{~m}$ ) from the tip of the tree using equation 19 .

\section{CONCLUSION}

This study demonstrates how an existing volume equation can be changed into compatible taper equation using an integration technique. The system is flexible enough to estimate merchantable volume of any section, height for any diameter, and diameter for any height based on only easily measurable parameters such as diameter at breast height and height. A taper equation is also being developed that predicts limit top diameter at any length and merchantable length for any specific merchantable diameter. In many practical applications, the user of such equations needs to know the outside-bark diameter at a given distance up the bole or, conversely, information may be desired on the length at which a given outsidebark diameter can be expected to occur. The results of this study will be useful in estimating the portions of the total tree volume in different use categories and reduce computing costs in forest inventory compilation.

\section{REFERENCES}

1. BMDP (1990). Statistical Software Manual Vol. 1, 2 and 3. Cork Technology Park, Ireland.

2. Bruce, D., Curtis, R.O. and Vancovering, C. (1968). Development of a system of taper and volume tables for red alder. Forest Science 14(3):339-350.

3. Clutter, J.L. (1980). Development of taper functions from variable-top merchantable volume equations. Forest Science 26(1):117-120.

4. Clutter, J.L., Fortson, J.C., Pienaar, L.V., Brister, G.H. and Bailey, R.L. (1983). Timber Management: A Quantitative Approach. John Willey and Sons. New York.

5. Demaerschalk, J.P. (1973). Integrated systems for the estimation of taper and volume. Canadian Journal of Forest Research 3(1):90-94.

6. Evert, F. (1976). Compatible systems for the estimation of tree and stand volume. Forestry Chronicle 52(1):15-16.

7. Kozak, A., Munro, D.D. and Smith, J.H.G. (1969). Taper functions and their application in forest inventory. Forestry Chronicle 45(4):278-283.

8. McTague, J.P. and Bailey, R.L. (1986). Simultaneous total and merchantable volume equations and a compatible function for loblolly pine. Canadian Journal of Forest Research 17:87-92.

9. Minitab (1995). User's guide. Release 10Xtra for Window's ${ }^{\mathrm{TM}}$ and Micintosh ${ }^{\mathrm{R}}$.

10. Munro, D.D. and Demaerschalk, J.P. (1974). Taperbased versus volume-based compatible estimating systems. Forestry Chronicle 197-199. 
11. Philip, M. (1994). Measuring Trees and Forests. CAB international. Wallingford, UK, $310 \mathrm{pp}$.

12. Reed, D.D. and Green, E.J. (1984). Compatible stem taper and volume ratio equations. Forest Science 30(4):977-990.

13. Tesfaye Teshome (1996). A growth and yield model for C. lusitanica in Munessa Shashemene State
Forest Project, south Ethiopia. Ph.D. Thesis. University of Aberdeen, Scotland, UK, 242 pp.

14. Tesfaye Teshome and Petty, J.A. (2000). Site index equation for Cupressus lusitanica stands in Munessa Forest, Ethiopia. Forest Ecology and Management 126:339-347. 